\title{
O uso da transmídia por editoras brasileiras
}

\author{
The use of transmedia by Brazilian publishers
}

\section{Camila Augusta Pires de Figueiredo}

Universidade Federal de Minas Gerais - UFMG - Minas Gerais - Brasil

\begin{abstract}
Resumo: Neste artigo, examinaremos alguns casos em que a transmídia foi utilizada por editoras brasileiras como ferramenta de criação de mídias suplementares aos seus livros. Além do próprio caráter do fenômeno transmídia, que se relaciona aos novos modos de escrita e leitura, e de produção e consumo de mídias na atualidade, interessa-nos analisar o propósito dos projetos transmídia elaborados pelas casas editoriais brasileiras, bem como as mídias e estratégias empregadas por elas. A partir da observação dos exemplos coletados, buscaremos traçar um perfil dos gêneros literários escolhidos, do público-alvo, das mídias empregadas e dos objetivos almejados.
\end{abstract}

Palavras-chave: Transmídia. Edição. Editora.

Abstract: In this paper we examine some cases in which transmedia was used by Brazilian publishing houses as a tool for creation of supplementary media to their books. Besides the characteristics of the transmedia phenomenon, related to the new modes of writing and reading, and of production and consumption of media in contemporary times, we are interested in analyzing the goals of the transmedia projects developed by Brazilian publishing houses, as well as the media and strategies employed by them. From the observation of the examples collected, we aim to establish a pattern of the literary genres chosen, the target audience, the media used and the goals aspired.

Keywords: Transmedia. Publishing. Publishing house. 


\section{Introdução}

Desde o final da década de 1970, mudanças tecnológicas e econômicas fizeram surgir na indústria do entretenimento um novo tipo de produto, denominado franquia. Nesse tipo de produção, o conteúdo não se concentra somente em uma mídia, mas projeta-se por meio de extensões e espalha-se através de outras mídias e de produtos licenciados, em um "empenho coordenado em imprimir uma marca e um mercado a conteúdos ficcionais" (JENKINS, 2009, p. 47). As franquias se inserem em um novo panorama cultural contemporâneo, chamado por Henry Jenkins de "cultura da convergência", que abrange os "fluxos de conteúdo através de múltiplas plataformas de mídias [e a] cooperação de múltiplos mercados midiáticos" (JENKINS, 2009, p. 29).

Um elemento muitas vezes presente nas franquias é a narrativa transmídia. De acordo com Elizabeth Evans, o termo "narrativa transmídia" [transmedia storytelling] foi utilizado pela primeira vez por Marsha Kinder e Mary Celeste Kearney como uma prática promocional envolvendo merchandising, adaptações, sequências e franquias (EVANS, 2011, p. 20-21). A narrativa transmídia designa a utilização de várias plataformas midiáticas que convergem para contar uma história, sendo que cada novo texto contribui de forma distinta para tal. Uma vez que um único texto não conseguiria abranger todo o conteúdo da narrativa, um texto central oferece vários pontos de acesso ao enredo, pontos esses que são explorados em outras mídias tais como jogos digitais, histórias em quadrinhos, sites, vídeos online, blogs, redes sociais etc. Assim, através da narrativa transmídia, pode-se, por exemplo, desenvolver histórias de personagens secundários, apresentar outras perspectivas da narrativa, completar "lacunas" da história, ou ainda fazer uma ponte entre um filme e sua sequência. No caso de narrativa transmídia ideal, não há redundância de informações, mas cada mídia oferece novos níveis de revelação, que se juntam para compor a narrativa completa da franquia.

O termo "narrativa transmídia" ganhou popularidade na última década na indústria cultural e do entretenimento e tem sido amplamente utilizado por artistas, produtores, marcas, desenvolvedores de jogos, críticos e estudiosos. A definição mais comumente utilizada para caracterizar o fenômeno transmidiático é a que Henry Jenkins propõe em 2003 na coluna para a Technology Review, cujos parâmetros foram posteriormente retomados em seu livro Cultura da convergência. Para ele, a transmídia designa um novo tipo de narrativa, em que a história "se desenrola por meio de múltiplas plataformas de mídia, com cada novo texto contribuindo de maneira distinta e valiosa para o todo" (JENKINS, 2009, p. 138). De acordo com Jenkins, esse fluxo de conteúdo através de múltiplos canais de mídia é quase inevitável nesta era de convergência de mídias.

A transmídia se apoia em uma tríade: a convergência dos meios de comunicação, a cultura participativa e a inteligência coletiva. A convergência dos meios de comunicação se dá por meio dos "fluxos de conteúdo através de múltiplas plataformas de mídias", da "cooperação entre múltiplos mercados midiáticos" e do "comportamento migratório dos públicos dos meios de comunicação"; a convergência não se dá pela união de aparelhos, mas "ocorre dentro dos cérebros dos consumidores individuais e em suas interações sociais com outros" (JENKINS, 2009, p. 29-30). A cultura participativa contrasta com a noção de passividade do público, que abandona o papel de simples consumidor de produtos de mídias e passa a participar, interagir e até mesmo produzir seu próprio conteúdo midiático. A expressão "inteligência coletiva", cunhada pelo teórico francês Pierre Lévy, refere-se à estratégia de consumo encontrada para fazer frente ao grande fluxo de informações dos nossos dias: "[p]or haver mais informações sobre determinado assunto do que alguém possa guardar na cabeça, há um incentivo extra para que conversemos entre nós sobre a mídia que consumimos." (JENKINS, 2009, p. 30). Primeiramente, as informações são coletadas conforme os recursos e habilidades individuais; posteriormente, de modo semelhante ao que fazemos com as peças de um quebra-cabeça, esses pedaços de informação são unidos. 
Em seu blog Confessions of an Aca-Fan, Jenkins descreve o fenômeno como "uma lógica para pensar sobre o fluxo de conteúdo que atravessa mídias" (JENKINS, 2011) ${ }^{1}$. Na prática, portanto, a narrativa transmídia é uma estratégia normalmente utilizada para (a) fazer uma ponte entre um texto principal - geralmente o filme - e suas sequências; (b) prenunciar evoluções no enredo de uma obra; (c) expandir a narrativa ou completar suas lacunas; (d) desenvolver histórias de personagens secundários, outros detalhes e perspectivas da narrativa; (e) oferecer um apoio para o ingresso de um novo público à franquia; (f) construir universos que não podem ser esgotados em uma só mídia. Economicamente, trata-se de um projeto vantajoso para os produtores, pois acaba por conquistar consumidores de diferentes nichos e aumentar o engajamento do público. Assim, a compreensão da narrativa transmidiática se dá no cruzamento de várias mídias, em um sistema de rede inter e multitextual que gerará uma experiência interpretativa ampliada e complexa. Esta é, aliás, uma das características preponderantes do fenômeno transmidiático.

Posteriormente, Jenkins reelabora parcialmente o conceito, ampliando-o para além da narrativa. Assim, o autor passa a compreender o fenômeno como a expansão de determinado conteúdo em várias plataformas de maneira coesa, criando um mundo ficcional que pode alcançar públicos consumidores das mais diversas mídias. Seguindo essa nova concepção, a expressão foi sendo gradualmente substituída pelo termo geral "transmídia", que passou a ser utilizado não apenas por narratologistas, mas também por jornalistas, profissionais de marketing e de comunicação, bem como por equipes especializadas na criação de conteúdos transmídia para promoção e divulgação de um determinado produto ou conjunto de produtos de mídia.

A utilização e o estudo da transmídia se popularizaram nas últimas duas décadas por causa,

\footnotetext{
1 "(...) one logic for thinking about the flow of content across media." Tradução minha.
}

entre outros fatores, das várias funções que ela pode assumir, bem como por se caracterizar como um fenômeno transdisciplinar, que serve como objeto de estudo de diversas áreas como Letras (Linguística e Literatura), Comunicação, Jornalismo e Marketing. Isso porque a transmídia reflete as novas formas de se contar, recontar e consumir (ouvir/ver/assistir/jogar etc.) histórias, típicas da contemporaneidade e resultante da multiplicidade e do acesso às novas mídias $^{2}$.

De fato, a transmídia impacta não apenas o modo de consumo mas também o modo de produção dos produtos culturais contemporâneos. Há uma nova lógica de produção e distribuição desses projetos, o que resulta em outras formas de circulação, marketing e consumo de produtos culturais. $\mathrm{Na}$ produção de livros, por exemplo, observamos que hoje algumas editoras não se preocupam somente com a publicação de livros impressos, mas precisam de profissionais com competências nas mais variadas mídias que possam estabelecer parcerias e cronogramas de lançamento em mercados nos quais - livro é apenas um dos produtos que serão consumidos. O editor assistente ou o editor chefe passa a ser um elaborador e avaliador de conteúdos em múltiplas plataformas, e não apenas na mídia impressa.

Da mesma forma, a dinâmica transmídia altera o modo de leitura e consumo dos produtos culturais, já que o público dessas produções não se restringirá ao leitor do livro, mas provavelmente (se o projeto for bem-sucedido) incluirá também 0 jogador, o internauta, o espectador, ou, usando o termo de Janet Murray (2003) para designar aquele que participa da construção de uma cibernarrativa, o "interator".

Torna-se necessário, então, atentar para o perfil desse novo público, para as novas habilidades que lhe são exigidas e para o modo como recebe e tem acesso a esse tipo de produção. Portanto, no

\footnotetext{
2 Apesar de não ter necessariamente de fazer uso das novas tecnologias (pode-se muito bem criar uma narrativa que comece como episódios em uma revista ou jornal, continue em um livro e termine em uma revista em quadrinhos), a transmídia encontra ambiente propício nas novas mídias - como a internet, os jogos digitais, os dispositivos móveis etc.
} 
caso em questão, é importante que as editoras que se propõem a desenvolver projetos transmídia tenham em mente que a leitura do livro será apenas uma parte da experiência do seu público com a narrativa.

A seguir examinaremos alguns casos em que a transmídia foi utilizada por editoras brasileiras como ferramenta de criação de mídias suplementares aos seus livros. A partir da análise dos projetos transmídia criados, busca-se traçar um perfil dos gêneros literários escolhidos, do público-alvo, das mídias empregadas e dos objetivos almejados.

\section{Projetos editoriais transmídia}

Em 2011, a Aleph, editora que detém os direitos da tradução para o português do famoso livro Cultura da convergência de Henry Jenkins, decidiu colocar na prática os princípios da transmídia para oferecer novas experiências de leitura a seu público, por meio da promoção de conteúdos multiplataformas.

Direcionada ao público juvenil, a série de cinco volumes Alma e Sangue, de Nazarethe Fonseca, é ambientada em São Luís, no Maranhão, e conta a história da sedutora Kara, que é raptada por Kmam, um vampiro de 400 anos, por quem acaba se apaixonando.

Após publicar os livros, a Editora Aleph, especializada em ficção científica e literatura young adult, se uniu à Delicatessen Filmes para a produção de uma websérie. Tratava-se naquele momento de uma iniciativa inédita no mercado editorial brasileiro: era a primeira vez que uma editora se associava a uma produtora para a criação de curtas-metragens relacionados a histórias de livros. A série, que trazia uma narrativa inédita ao conteúdo dos livros, era composta por três vídeos com cerca de quatro minutos de duração cada, que ficavam disponíveis em um site próprio e eram divulgados no blog e nas redes sociais da editora (BLOG DA ALEPH, 2011).

\footnotetext{
3 Hoje o site <http://www.almaesangue.com.br> não está mais disponível, mas os vídeos produzidos podem ser assistidos no endereço <https://vimeo.com/album/3449505>, conforme acesso do dia 18 ago. 2017.
}

Além dos vídeos, o site ainda continha outros contos inéditos da autora, galeria de fotos e wallpapers.

De acordo com Adriano Fromer, editor da Aleph, "a ideia foi seguir o conceito [de narrativa transmídia] à risca: desenvolver um roteiro inédito, que agregasse experiência ao fã, mas que, ao mesmo tempo, fosse atraente para conquistar novos leitores" (ALMA E SANGUE, 2011). Assim, além de expandir a narrativa e proporcionar uma experiência mais profunda para os fãs, a websérie almejou oferecer um novo ponto de acesso do público à saga, como um convite para adentrar o mundo ficcional dos jovens vampiros maranhenses.

Em 2013, foi a vez da Gutenberg, selo da Editora Autêntica de literatura para adolescentes e jovens adultos, experimentar no campo da transmidialidade. Coincidentemente, o projeto transmídia desenvolvido pela editora utilizou outras plataformas para explorar a mesma temática de jovens vampiros. Na série Red Luna, três clãs de vampiros disputam uma trama milenar, que se estende desde os tempos mitológicos até os tempos atuais. O primeiro livro, $A$ biblioteca do czar, de Gabriel Morato e Marcos Inoue, lançado em 2012, narra a história do clã Varnis durante as Guerras Napoleônicas. O segundo livro, $A$ profecia de Samsara, escrito por Leticia Vilela e lançado em 2014, é ambientado na Índia antiga e conta a história do clã Devas.

A série foi concebida desde o início como um projeto transmídia: além dos dois livros, foram previstas extensões em outras plataformas midiáticas. De acordo com o projeto, às histórias em quadrinhos, elaboradas em estilo mangá e disponibilizadas no site www.redluna.com.br, caberia introduzir ou concluir as histórias dos livros. Estes, por sua vez, narrariam tramas subjacentes a um jogo, que seriam posteriormente exploradas em um cardgame online.

Ao que tudo indica, o cronograma de lançamento dos produtos que compõem o projeto sofreu atrasos. Em 2014 já era anunciado o jogo de cartas online, ambientado após a Segunda Guerra Mundial, em um cenário no qual tecnologias nazistas 
teriam origens místicas (UM UNIVERSO, 2014). O site das empresas responsáveis pelo desenvolvimento do cardgame Red Luna - Spell of the Sun, a Stuplendo Entertainment e a Spikez Produções, anuncia mais informações para o ano de 2017 (RED LUNA, s.d.). Não foram localizadas informações sobre o outro jogo mencionado como parte do projeto transmídia.

Em 2016, a editora Peirópolis e a Ciclope anunciaram o lançamento do livro transmídia Poemas de brinquedo, de Álvaro Andrade Garcia. Apesar de não se limitar a ela, a Peirópolis destaca-se pelas obras direcionadas aos públicos infantojuvenil e jovens adultos, como a coleção de clássicos da literatura mundial em quadrinhos. A Ciclope, ateliê de arte digital situado em Belo Horizonte, cria e gerencia projetos de arte e de publicação nas mais variadas mídias, em especial nas áreas de turismo, cultura, educação e sustentabilidade.

O projeto concebido para Poemas de brinquedo prevê, além da versão impressa do livro em formato de cartas para brincar, uma versão digital em formato de app interativo para dispositivos móveis. Porém, ao contrário do que se possa imaginar, foi a partir da seleção dos poemas que integrariam o app que se pensou na obra impressa, e não o contrário.

Nesse projeto, os poemas do livro, selecionados a partir de uma certa aptidão visual e/ou sonora para publicação em meio digital, recebem efeitos gráficos, de animação e de vocalização que traduzem semioticamente os poemas escritos a diferentes modalidades de mídias. Em seguida,

[a] partir dessa obra finalizada em app foi pensada a obra impressa, em forma de cartas para manusear e brincar, acondicionadas numa luva que também convida o leitor a acessar o app através de um QR code na contra capa. (PEIROPOLIS E CICLOPE, 2016)

Por meio do app em celulares e tablets, o modo de acesso aos poemas de brinquedo - palavras inventadas, trava-línguas, histórias engraçadas extrapola a visualização da palavra escrita; a leitura vira uma brincadeira que envolve sentidos $e$ competências das mais variadas: tocar na tela com os dedos, ouvir as canções e os poemas com sotaques, interagir com as animações, enunciar os sons, observar as tipografias, as cores, os ritmos. E o livro impresso, mais do que um objeto a ser lido, dispensa a encadernação e almeja ser declamado em leituras performativas e manuseado em brincadeiras.

Percebe-se nesse projeto editorial o esforço de uma equipe de criadores especializados em diferentes mídias - autor, editor, animador, designer gráfico, designer de som e programador (POEMAS, s.d.) -, trabalhando conjuntamente para explorar as possibilidades interativas, sonoras, visuais e lógicas dos poemas, de acordo com as especificidades de cada mídia selecionada.

Em 2017, duas iniciativas de projetos transmídia foram anunciadas no mercado editorial brasileiro: uma da editora Novo Conceito e outra da Intrínseca. No primeiro caso, trata-se do projeto relacionado à aquisição dos direitos de tradução do livro Caraval, de Stephanie Garber, best-seller do New York Times, que já teve seus direitos de adaptação para o cinema comprados pela Twentieth Century Fox.

Caraval conta a história de duas irmãs que vivem com o pai, o cruel governador de uma ilha. $O$ desejo das garotas é escapar da ilha e, para isso, o convite para participarem do Caraval, uma apresentação mágica que ocorre uma vez por ano, parece ser a oportunidade perfeita para se libertarem - para sempre talvez - de uma existência de medo e submissão.

O projeto transmídia prevê um site exclusivo para o lançamento, por meio do qual o leitor pode ter acesso ao universo do livro, um reality show da era medieval, e a desafios semanais que, uma vez superados, ofereceriam ao leitor um bônus para compra de uma edição especial do livro. Pretende-se por essa estratégia oferecer um ponto de acesso ao público para conhecer o mundo ficcional e partes da história antes mesmo de o livro ser lançado, a fim de criar expectativas, buscar engajamento e aguçar a curiosidade do potencial leitor. 
No caso do projeto da Intrínseca, trata-se de um evento ficcional relacionado ao livro Five Nights at Freddy's: Olhos prateados, uma expansão do universo do famoso jogo eletrônico de terror Five Nights at Freddy's, lançado em 2014 e desenvolvido por Scott Cawthon. A partir de uma perspectiva em primeira pessoa, o jogo se passa na Pizzaria Freddy Fazbear, onde o jogador deve agir como um guarda noturno, sobrevivendo por seis noites enquanto é perseguido por outros personagens. No livro, Charlie é convidada a participar de uma homenagem a um de seus amigos de infância, morto dez anos antes em circunstâncias misteriosas, dentro da pizzaria que pertencia ao pai dela, agora abandonada.

No blog da editora, um suposto desaparecimento da editora assistente de aquisições da empresa é reportado, após a leitura de um trecho desse livro de terror e mistério. Ao final da reportagem do blog da editora, depois das mensagens que supostamente teriam sido enviadas pela garota antes do seu desaparecimento, é possível ler uma informação direcionada ao público-alvo: "E, se você gosta de histórias assustadoras sobre uma galerinha da pesada se envolvendo em confusões sobrenaturais, ou se já conhece a série de jogos Five Nights at Freddy's e quer entender melhor a história por trás dos sustos, leia um trecho de Olhos prateados." (UMA NOITE, 2017)

Nota-se nesse caso o emprego de uma função extremamente popular da transmídia, que é a elaboração de objetos e relatos ficcionais buscando a verossimilhança, num jogo em que o mundo ficcional extrapola seus limites e transborda para o real. Esses objetos verossímeis criam uma ilusão (nem sempre óbvia) entre realidade e ficcionalidade, pois buscam ser compreendidos como se fossem reais ${ }^{4}$.

\footnotetext{
${ }^{4}$ Além da criação de objetos ficcionais verossímeis, outras características preponderantes da transmídia se referem ao modo de construção de personagens e mundos ficcionais e à utilização de elementos mitológicos e icônicos. Essas características são investigadas de maneira mais detalhada no Capítulo 2 da tese intitulada Em busca da experiência expandida: revisitando a adaptação por meio da franquia transmidiática, disponível em <https://goo.gl/GcyMSd>, de minha autoria.
}

\section{Considerações finais}

A partir da análise dos projetos selecionados, observa-se uma preferência pela utilização da transmídia para criação de conteúdo destinado aos públicos pré-adolescente e jovem adulto; apenas o projeto "Poema de brinquedo" se destina ao público infantil. Isso fala sobre o hábito de consumo do público dessas faixas etárias, acostumado a utilizar o ambiente virtual para assistir a vídeos, jogar jogos digitais e interagir com outras pessoas, entre outras ações.

Dos cinco projetos selecionados, dois abordam a temática de vampiros, muito provavelmente buscando seguir o sucesso da Saga Crepúsculo, escrita entre 2005 e 2008 por Stephenie Meyer e que teve seu boom no Brasil em 2008, com o lançamento da primeira adaptação para o cinema. Dos outros três projetos analisados, um pertence ao gênero de aventura e fantasia; outro pode ser classificado no gênero do terror; e o último, ao de poesia. Percebe-se na escolha das temáticas uma tendência para os gêneros de ficção de aventura, de mistério, terror e fantasia, com elementos místicos e mitológicos. Além disso, observa-se que os protagonistas pertencem à mesma faixa etária do público: adolescentes ou jovens adultos. A exceção entre os projetos examinados seria o "Poema de brinquedo".

A respeito das mídias empregadas, observa-se a dependência das mídias digitais em todos os casos. No caso do projeto da Aleph, na integração entre o livro, a websérie e os recursos do site; no da Gutenberg, na relação entre o livro, as histórias em quadrinhos online, os demais recursos do site, o jogo e o cardgame online. No projeto da Peirópolis, a expansão se dá do livro para o app (ou vice-versa); e no da Novo Conceito, entre o livro e o site promocional. Finalmente, no projeto da Intrínseca, um detalhe interessante é que o livro não seria a mídia principal do projeto transmidiático, mas, juntamente com o blog - que faz uma conexão com a história -, uma extensão transmídia do jogo.

Em quatro dos cinco projetos escolhidos, as outras mídias foram utilizadas para explorar de 
maneira mais detalhada certos aspectos da narrativa ou para apresentar ao leitor momentos anteriores ou posteriores à história do livro. Já no caso de Poemas de brinquedo, o app oferece modalidades de mídias diferentes do poema escrito, ativando percepções sensoriais distintas do olhar na leitura: o leitor pode tocar, ouvir, declamar e brincar com os poemas.

O que todos os casos examinados têm em comum, no entanto, é a utilização da transmídia com o propósito de oferecer ao leitor uma experiência expandida em relação à leitura dos livros. Assim, num contexto transmídia, a história se expande para além dos limites das páginas do livro impresso, que se torna apenas um dos pontos de acesso à narrativa.

\section{Referências}

ALMA E SANGUE: saga ganha websérie. $H Q$ maniacs. 19 jan. 2011. Disponível em: <https://goo.gl/B4ivsC>. Acesso em: 25 ago. 2017.

BLOG DA ALEPH. Alma e Sangue, a websérie: 0 primeiro episódio está no ar! 21 jan. 2011. Disponível em: <https://goo.gl/iZLDQ2>. Acesso em: 25 ago. 2017.

EVANS, Elizabeth. Transmedia Television: Audiences, New Media and Daily Life. New York/London: Routledge, 2011.

JENKINS, Henry. Transmedia Storytelling. Technology Review. 15 jan. 2003. Disponível em: <https://www.technologyreview.com/s/401760/tran smedia-storytelling/>. Acesso em: 25 ago. 2017.

JENKINS, Henry. Cultura da convergência. 2ª ed. ampl. e atual. São Paulo: Aleph, 2009.

JENKINS, Henry. Transmedia 202: Further Reflections. Confessions of An Aca-Fan. 31 jul. $2011 . \quad$ Disponível em: <http://henryjenkins.org/2011/08/defining_transme dia_further_re.html>. Acesso em: 25 ago. 2017.

MURRAY, Janet. Hamlet no holodeck: o futuro da narrativa no ciberespaço. São Paulo: Unesp/Itaú Cultural, 2003.
PEIRÓPOLIS E CICLOPE lançam livro transmídia de poesia expandida, em papel, epub e formato app interativo para crianças e adultos. 29 jun. 2016. Disponível em: <https://goo.gl/1hTwCb>. Acesso em: 25 ago. 2017.

POEMAS de brinquedo, os desafios de uma publicação transmídia. s.d. Disponível em: <http://www.editorapeiropolis.com.br/2017/07/31/p oemas-de-brinquedo-os-desafios-de-umapublicacao-transmidia/>. Acesso em: 25 ago. 2017.

RED LUNA: Spell of the Sun. s.d. Disponível em: $<\mathrm{http}: / /$ redluna.stuplendo.com/>. Acesso em: 25 ago. 2017.

UM UNIVERSO nacional de vampiros: conheça o projeto "Red Luna". 28 jan. 2014. Disponível em: <https://goo.gl/hxayJY>. Acesso em: 25 ago. 2017.

UMA NOITE assustadora com Freddy. 17 maio 2017. Disponível em: <http://www.intrinseca.com.br/blog/2017/05/umanoite-assustadora-com-freddy/003E $>$. Acesso em: 25 ago. 2017.

\section{COMO CITAR ESSE ARTIGO}

FIGUEIREDO, Camila Augusta Pires de. O uso da transmídia por editoras brasileiras. Signo, Santa Cruz do Sul, v. 43, n. 76, mar. 2018. ISSN 1982-2014. Disponível em: <https://online.unisc.br/seer/index.php/signo/article/view/10550>. Acesso em: doi: http://dx.doi.org/10.17058/signo.v43i76.10550. 